\title{
Estimation of genetic erosion on Ethiopian tetraploid wheat landraces using different approaches
}

\author{
Alemayehu Zemede Lemma ${ }^{a}$, Firew Mekbib $^{\mathrm{b}}$, Kebebew Assefa $^{\mathrm{a}}$ and Zewdie Bishaw $^{\mathrm{c}}$ \\ ${ }^{a}$ Ethiopian Institute of Agricultural Research (EIAR), Addis Ababa, Ethiopia \\ ${ }^{b}$ Faculty of Agriculture and Environmental Sciences, School of Plant Sciences, Haramaya University, DireDawa, Ethiopia \\ ${ }^{c}$ International Center for Agricultural Research in Dry Area (ICARDA), Addis Ababa, Ethiopia
}

\begin{abstract}
The demand and use of improved crop varieties by farmers has increased in the central highlands of Ethiopia, where continuous loss of local traditional varieties has been occurring in the last two to three decades. The objectives of the study were to assess the extent of genetic erosion and perception of farmers and associated causes for the reduction of traditional farmers' varieties. Direct field assessment covering 56 wheat farms and a survey in which 149 farmers participated were carried out in three districts of central Ethiopia. Based on data collected during direct farm assessment, the loss of genotypes was found to be $88 \%$ in Ada followed by $80 \%$ and $60 \%$ in Lume and Gimbichu districts, respectively. The farmer survey indicated an even greater loss of diversity of $100 \%$ in Ada followed by Lume (93\%) and Gimbichu (67\%). Diseases and pests as well as shorter growing seasons associated with climate change were identified as main causes for farmers to switch to modern varieties. The expansion of high yielding improved bread and durum wheat varieties also contributed to gradually replace local durum wheat varieties by local farmers of these districts. Overall, genetic erosion of tetraploid wheat varied among the three districts of central Ethiopia. Reductions in the number of farmers and area coverage in the study districts could be used as good indicators for the existence of genetic erosion.
\end{abstract}

Keywords: Direct farm assessment, Genetic erosion indicators, Genetic integrity, Landraces, Tetraploid wheat

Citation: Zemede Lemma, A., Mekbib, F., Assefa, K., Bishaw, Z. (2021). Estimation of genetic erosion on Ethiopian tetraploid wheat landraces using different approaches. Genetic Resources 2 (4), 66-71. doi: 10.46265/genresj.PYBZ4246.

(C) Copyright 2021 the Authors.

This is an open access article distributed under the terms of the Creative Commons Attribution License (CC BY 4.0), which permits unrestricted use, distribution, and reproduction in any medium, provided the original author and source are

credited.

\section{Introduction}

Ethiopia is the largest wheat producer in Sub-Saharan Africa with about 1.6 million ha of durum and bread wheat (Central Statistical Agency, 2017). Wheat is one of the major cereal crops in the Ethiopian highlands, which range between 6 and $16 \mathrm{~N}$ latitude, 35 and $42 \mathrm{E}$ longitudes, and from $1500 \mathrm{~m}$ to $2800 \mathrm{~m}$ above sea level (masl). Ethiopia has already been identified as an important center of diversity for different crops. Durum wheat is a tetraploid wheat variety traditionally grown on heavy black clay soils (Vertisols) of the Ethiopian highlands between 1800-2700 masl, where it is mainly produced by small scale farmers. Durum wheat is suitable for manufacturing pasta products (e.g. macaroni, spaghetti); however, in Ethiopia it is also used for making "injera", a white leavened
Ethiopian bread made from grain flour, and other local foods. Durum wheat grown in Ethiopia is constituted by a few improved varieties and a large number of traditional farmers varieties, commonly referred to as landraces (Bechere et al, 2000; Eticha et al, 2006; Bishaw et al, 2014).Durum wheat is extensively cultivated and grown by a large number of farmers and a significant number of traditional farmers' varieties have been recorded in the central highlands of Ethiopia in the past 20 to 30 years (Negatu et al, 1992). Statistics on durum wheat production in Ethiopia from the past decades are difficult to obtain, they are usually lumped with bread wheat in reporting. The total area under wheat production in 1983was reported to be 625,590 ha of which $60-70 \%$ was estimated to be used forthe production of durum (Tesema, 1991). The following 
decades saw a drastic reduction in area coverage for durum wheat which dropped to around 50\% of total wheat production area (Gashawbeza et al, 2003). Recent reports indicated that the area coverage for durum has further declined to not more than $15-20 \%$ from a total 1.6 million ha of lands (Mengistu et al, 2016).

Introduction of modern varieties, improved production practices and problems associated with biotic stresses like crop pests and diseases as well as abiotic stresses such as droughts in traditional farming systems were among the major problems faced by the farmers leading to gradual replacement of traditional farmers' varieties. Genetic erosion is defined as "the loss of genetic diversity, in a particular location and over a particular period of time, including the loss of individual genes and the loss of particular combinations of genes such as those manifested in landraces or varieties" (FAO/IPGRI, 2002). It could be considered as a consequence of the loss of diversity in the farmer's field and will have a major effect on the future crop productions and productivity for indigenous crop species of Ethiopia. The problem has been increasing and is expected to be more aggravated for durum wheat than other cereal crops.

Several research reports from survey studies and farmers' discussion indicated loss of diversity on tetraploid wheat has increased faster than expected in different environments of Ethiopia. The reduction in number of farmers, traditional farmer varieties or landraces and area coverage confirmed the danger and extent of genetic erosion on tetraploid wheat, as reported in multiple studies. Teklu and Hammer (2006) reported genetic erosion of $88 \%, 100 \%$ and $78 \%$ for the durum wheat species Triticum durum, T. turgidum and T. dicoccon, respectively. In Harar Zuria, the same authors detected genetic erosion of $88.9 \%$ for T. durum and $100 \%$ for both $T$. turgidum and $T$. dicoccon. In the western Shoa zone of Ethiopia, genetic erosion reached $75 \%$ and $62 \%$ for tetraploid wheat species in Ambo and Dandi districts, respectively (Geleta and Gausgruber, 2013). In a similar study farmers identified 26 tetraploid wheat land races (21 from Akaki and 17 from Ejere), which were once widely grown in the area and of which only six were currently available; the average loss of diversity was thus estimated to be $77 \%$ (Tsegaye and Berg, 2007). Besides primary sources collected from a survey using semi-structured questionnaires and farmers' group discussions, this study also used direct field assessment to identify recently cultivated landraces and compare them to previously available landraces in the similar districts, calculating levels of genetic integrity and erosion based on the procedures of Hammer et al (1996). The reduction in numbers of farmers growing landraces and area of cultivation were identified as useful indicators for the existence of genetic erosion (Brown and Hodgkin, 2015).

The objectives of this present study were to calculate and estimate on farm genetic erosion and identify associated causes in three districts of central Ethiopia using different approaches. Results obtained from direct field assessments and observations as well as information collected from farmers' interviews and discussions were used to investigate the current status of durum landraces and to determine trends based on the number of farmers using landraces and the area of cultivation of the landraces.

\section{Materials and Methods}

\section{Study areas}

The study was conducted in three districts of the central highlands of Ethiopia based on direct observation, a semi-structured survey questionnaire and group discussions. Direct observation was conducted across three different routes which covered Gimbichu, Ada, and Lume districts during the 2017 cropping season (Figure 1). A survey questionnaire and group discussions were conducted in Ada, Lume and Gimbichu districts of the central highlands of Ethiopia in 2018. The three districts were purposely selected to represent the durum wheat agro-ecology environment of the East Shoa Zone: 1) Ada represents a midland wheat growing agroecology area,where modern crop varieties are assumed to be dominantly cultivated; 2) Lume represents a midland area where both landraces and modern wheat cultivars are believed to exist due to interventions by the Ethiopian Biodiversity Institute to recover the status of local in situ conservation; and 3) Gimbichu district represents wheat growing agro-ecology at high elevation and is an area where durum landraces are still extensively cultivated.

\section{Research methodology}

\section{Direct observations}

Direct wheat field assessment and identification of species and varieties of species was conducted in November 2017 along three routes passing through major wheat producing districts in the central highlands of Ethiopia (Figure 1). The survey was made on 56 wheat growing farms at approximately three to fivekilometer intervals when the crop was observed. The different wheat species were classified into modern bread or durum and tetraploid landraces based on their spike characteristics and uniformity. The number of landraces available in 2017 compared to the landraces recorded in 1992 was the basis for calculating genetic integrity and genetic erosion. Modern wheat (bread and durum) and landraces area coverage was calculated as percentage of each wheat species area to the total wheat area of the 56 farms visited during direct farm assessment.

\section{Survey study}

A survey on perception on use of landraces and genetic erosion was carried out to collect data from 149 farmers in three villages of the Ada, Gimbichu and Lume districts 


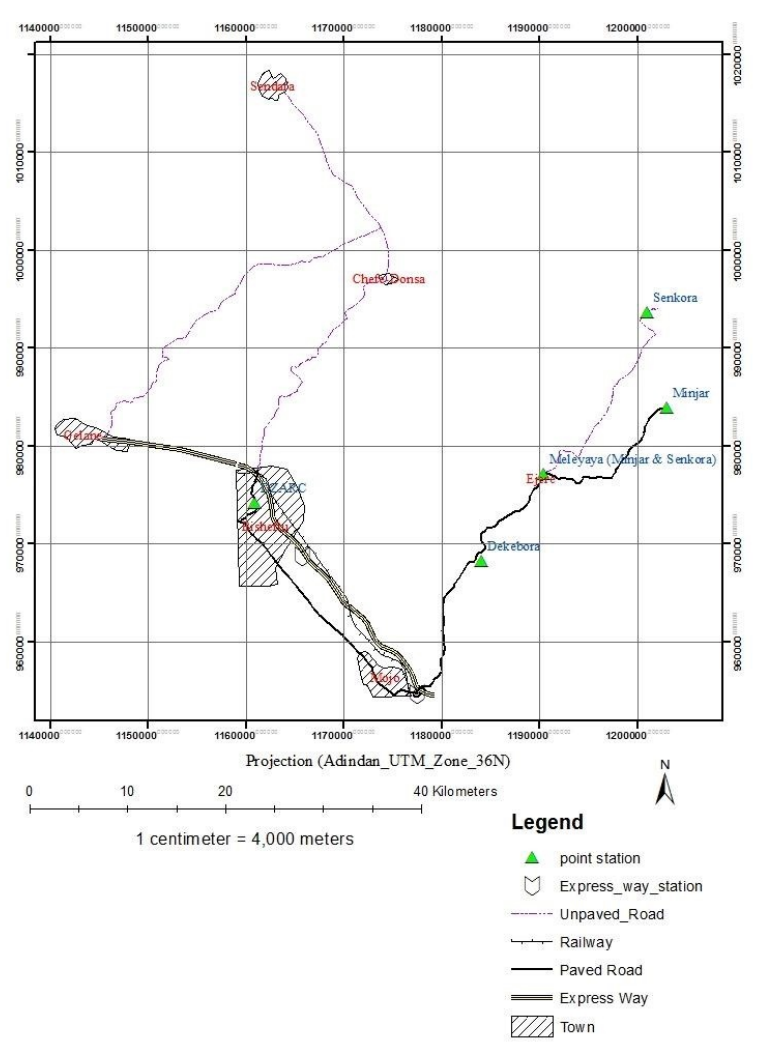

Figure 1. Travel routes for direct farm assessment.

using semi-structured questionnaires between 10 and 25 December, 2018.

\section{Group discussions}

Farmers' group discussions were held in Ada, Gimbichu and Lume districts between 20 and 25 December 2018 to collect information about the past and current status of landraces and to identify causes why farmers stopped growing landraces in the area. Three group discussions in each district consisted of 12-15 systematically selected farmers from surrounding villages, also taking into consideration gender representation.

\section{Data collection and summary}

Genetic erosion was calculated according to the formula of Hammer et al (1996): GE = 100\% - GI, where GE is genetic erosion and GI is genetic integrity, which is given as: $\mathrm{GI}=\mathrm{N}_{2} / \mathrm{N}_{1} \times 100$. The number of farmers cultivating landraces and their relative area coverage were determined. The number of landraces cultivated recently as compared to previous number was the basis for calculation of genetic erosion. In the present study, the number of landraces grown by the farmers 25 years ago (Negatu et al, 1992) was considered as $\mathrm{N}_{1}$ and the number of landraces recorded in 2017 represented $\mathrm{N}_{2}$.
Table 1. Genetic erosion on tetraploid wheat since 1992 in three districts of the central highlands of Ethiopia

\begin{tabular}{lllll}
\hline Districts & $\begin{array}{l}\text { landraces } \\
\text { cultivated } \\
\text { in 1992 }\end{array}$ & $\begin{array}{l}\text { landraces } \\
\text { cultivated } \\
\text { in 2017 }\end{array}$ & $\begin{array}{l}\text { Genetic } \\
\text { Integrity } \\
(\%)\end{array}$ & $\begin{array}{l}\text { Estimated } \\
\text { genetic } \\
\text { erosion } \\
(\%)\end{array}$ \\
\hline Gimbichu & 15 & 6 & 40 & 60 \\
Lume & 15 & 2 & 20 & 80 \\
Ada & 16 & 2 & 12.5 & 87.5 \\
\hline
\end{tabular}

\section{Results}

\section{Direct observation}

Genetic erosion occurred on tetraploid wheat after 25 years based on direct farm assessment (Table 1). The variation was significant on loss of diversity on tetraploid wheat at $0.01 \%$. The average genetic erosion across districts was $75.8 \%$, which is lower compared to previous reports (Geleta and Gausgruber, 2013). The loss of diversity on tetraploid wheat was found to be the highest in Ada (87.5\%) and lowest in Gimbichu (60\%) based on direct field assessment (Table 1).

The proportion of landraces compared to modern wheat varieties was lower in lower altitude than high altitude growing environments (Figure 2). In 2017 the proportion of landraces in altitudes above $2400 \mathrm{~m}$ were $70 \%$ while below $2400 \mathrm{~m}$ this dropped to about $30 \%$ compared to modern wheat.

\section{Number of farmers and area of cultivation}

Modern bread and durum wheat as well as tetraploid landraces area coverage were estimated based on random field visits and identification of wheat species found in the field and calculated as percentage of each wheat species area to the total wheat area in a given district.

In 2017 only $8.3 \%$ of farmers in Lume, about $23.5 \%$ in Ada and $40.7 \%$ in Gimbichu were growing local varieties. When the three districts were considered, only

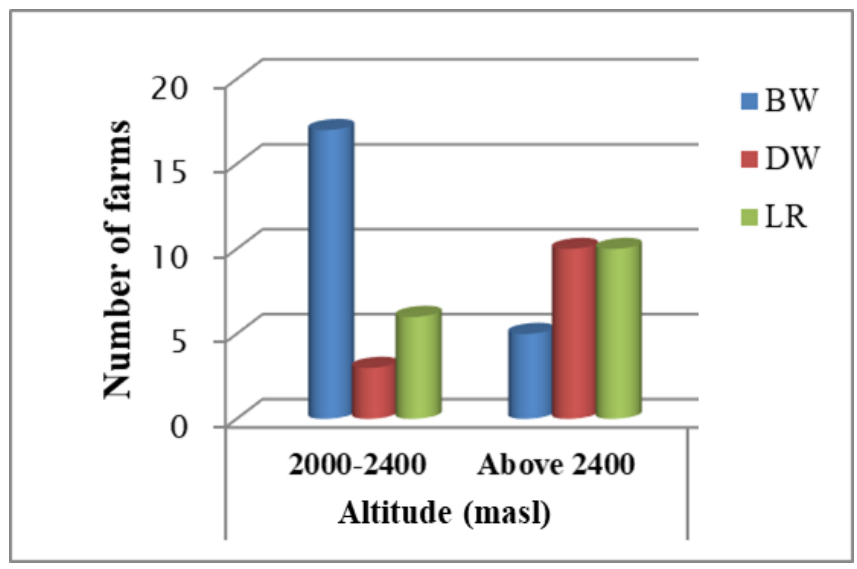

Figure 2. The number of tetraploid wheat (DW), local landraces (LR) and modern wheat varieties (BW) grown in different altitude zones based on direct field observations in 2017. 


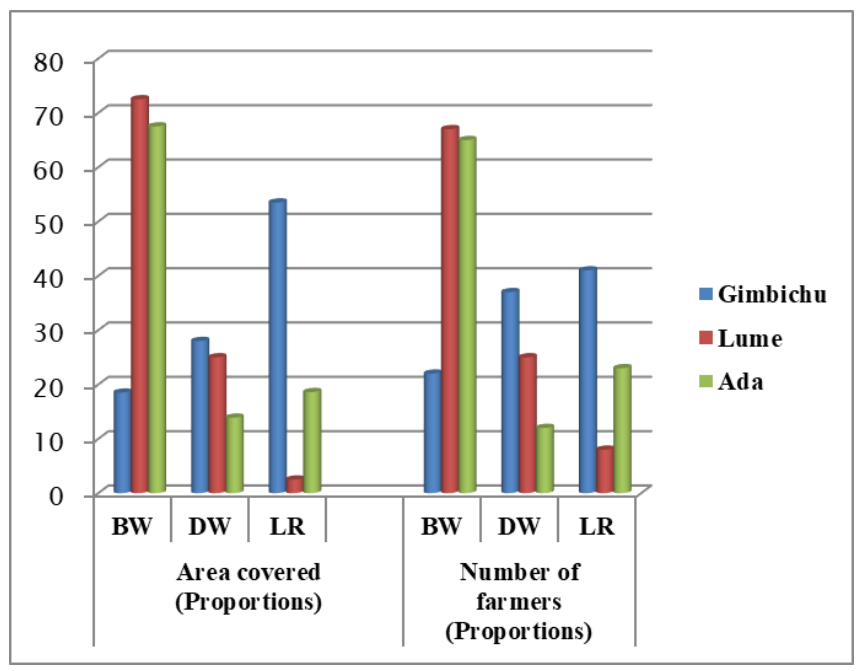

Figure 3. The proportion of landraces (LR), modern bread wheat (BW) and durum wheat (DW) varieties by area coverage and number of farmers in three Ethiopian districts in 2017 based on direct field observations on 56 farms in the districts.

$24.2 \%$ of farmers were growing local durum wheat varieties. On average $24.5 \%$ of wheat growing area was occupied by landraces across the three districts compared to modern wheat varieties. The highest area coverage was in Gimbichu (52.3\%) while the lowest was $2.5 \%$ in Lume (Figure 3 ).

\section{Farmers' survey}

In order to obtain a more pronounced picture of the estimated loss of genetic diversity in central Ethiopia, semi-structured interviews were conducted with 149 farmers from three communities in the three districts. Based on interviews with farmers, significant genetic erosion was observed in tetraploid wheat after 25 years (Table 2). The loss of diversity in tetraploid wheat reached up to $100 \%$ in Ada and was lowest in Gimbichu (67.7\%), with an average of $87 \%$, based on the survey.

In the 2018 growing season only $7.3 \%$ of farmers in the Lume district but $68.4 \%$ in Gimbichu were maintaining landraces of wheat. None of the farmers interviewed in Ada district were growing wheat landrace varieties. A similar trend was observed in cultivation area of landraces compared to modern varieties. The sample area coverage was $13.5 \%$ in Gimbichu and only

Table 2. Genetic erosion of tetraploid wheat since 1992 in three districts of the central highlands of Ethiopia based on semi-structured interviews with 149 farmers.

\begin{tabular}{|c|c|c|c|c|}
\hline Districts & $\begin{array}{l}\text { Durum } \\
\text { wheat } \\
\text { varieties } \\
\text { cultivated } \\
\text { in } 1992\end{array}$ & $\begin{array}{l}\text { Durum } \\
\text { wheat } \\
\text { varieties } \\
\text { cultivated } \\
\text { in } 2017\end{array}$ & $\begin{array}{l}\text { Genetic } \\
\text { Integrity } \\
(\%)\end{array}$ & $\begin{array}{l}\text { Estimated } \\
\text { genetic } \\
\text { erosion } \\
(\%)\end{array}$ \\
\hline \multicolumn{2}{|c|}{ Gimbichu 15} & 5 & 33.3 & 67.7 \\
\hline Lume & 15 & 1 & 6.7 & 93.3 \\
\hline Ada & 16 & - & - & 100.0 \\
\hline
\end{tabular}

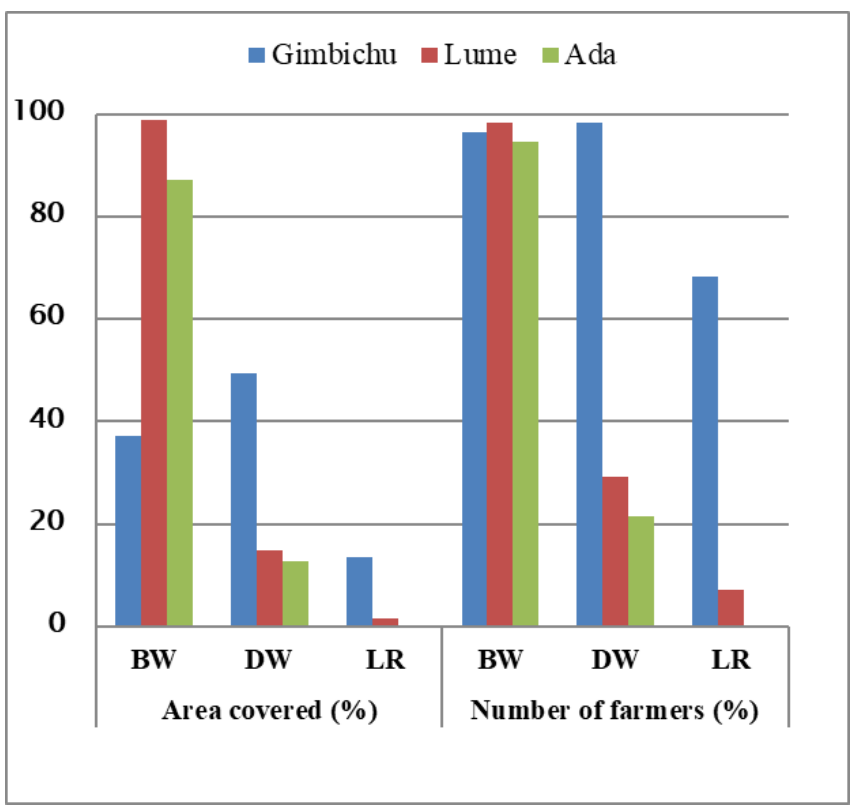

Figure 4. Percentage of landraces (LR) and modern bread wheat (BW) and durum wheat (DW) varieties by area coverage and number of farmers in three districts based on interviews with 149 farmers in 2018.

$1.5 \%$ in Lume. No farms were cultivating landraces in Ada district (Figure 4).

\section{Group discussions}

The reasons given by farmers on why they are currently not growing local varieties are presented in Table 3 . The most common reason accounting for high losses in all three districts were identified as diseases and pests, mainly stem rust, followed by terminal drought associated with a short growing season. The data also indicated that the availability and supply of better yielding improved bread and durum varieties gradually replaced local varieties inducing farmers of these districts to stop or reduce growing local durum wheat varieties (Table 3). The expansion of high value crops like tef and chickpea was also mentioned as cause for losses of local varieties in Ada and Lume districts, whereas in Gimbichu water logging and the difficulty of using landraces for making local injera and bread due to its hard seed were raised as reasons for replacing landraces with modern wheat varieties. Similar findings and reasons were reported by Tsegaye and Berg (2007) in studies conducted in Lume and Akaki districts of the central highlands of Ethiopia.

On the contrary, the existence of a short growing season resulted in change in crop variety from farmers' to modern varieties that could be suited to early planting. Use of high amounts of fertilizer associated with growing modern varieties have resulted in shifting from landraces to modern varieties particularly in Ada and Lume districts where high genetic erosion was observed. 
Table 3. Reasons for not growing local durum wheat landraces in 2018 in Ada, Lume, and Gimbichu districts, provided by farmers during the Group discussions.

\begin{tabular}{lllll}
\hline Causes of genetic erosion & $\begin{array}{l}\text { Ada } \\
\text { (N=37) }\end{array}$ & $\begin{array}{l}\text { Lume } \\
\text { (N=55) }\end{array}$ & $\begin{array}{l}\text { Gimbichu } \\
\text { (N=57) }\end{array}$ & $\begin{array}{l}\text { All } \\
\text { (N=149) }\end{array}$ \\
\hline Diseases and pests affecting landraces & 15 & 48 & 36 & 99 \\
Shorter growing season associated with climate change & 13 & 27 & 21 & 61 \\
Improved bread wheat & 6 & 23 & 13 & 42 \\
Improved durum wheat & 4 & 15 & 20 & 39 \\
Water logging & - & - & 18 & 18 \\
Unavailability of seed for the landraces & 7 & 2 & 6 & 11 \\
Utilization (durum landraces not suited for production of injera & - & - & & 6 \\
and bread) & & & - & 5 \\
Shortage of land and urbanization & 5 & - & - & 4 \\
Expansion of high value crops (tef and chickpea) & 4 & - & & \\
\hline
\end{tabular}

\section{Discussion}

The results indicated that on average $75.8 \%$ and $87 \%$ genetic erosion was observed on tetraploid wheat after 25 years based on direct farm assessment and survey study, respectively. The levels of loss observed from both approaches appear to be similar to that reported in Western Ethiopia (Geleta and Gausgruber, 2013). The loss observed was higher in Ada and Lume, situated at lower altitude, than in the high altitude zone above 2400 masl of Gimbichu district, where significant areas of land are still used to grow landraces. This difference can be attributed to the fact that both Ada and Lume districts have similar agro-ecology, access to big market centers and are also near to the Debre-Zeit Agricultural Research Center where a lot of improved wheat cultivars are developed, demonstrated and distributed. Modern wheat and tef crops are more expanded (Assefa et al, 2015) and could also be major causes for loss of diversity in the Ada and Lume districts. The presence of higher diversity in Gimbichu district might be associated to the merits of landrace adaptation and yield stability (Berg, 2009). Similarly, Tsegaye and Berg (2007) reported $77 \%$ genetic erosion and relative diversity for tetraploid wheat in Ejere, a high elevation district of central Ethiopia.

Our study demonstrated a correlation between the extent of genetic erosion and altitude. This indicates the relative importance of focusing further landrace collection and conservation efforts on altitudes above 2400 masl to capture more diversity. The study further confirmed the existence of better occupation in terms of area coverage and maintenance of landraces by large numbers of farmers in Gimbichu as compared to Ada and Lume. This could be due to the expansion of modern wheat varieties at the expense of the landraces in the latter districts as illustrated in Figure 3 and Figure 4 and confirmed by farmers' group discussions. Negatu et al (1992) reported that $64 \%$ of sample farmers grew local durum wheat varieties in the same districts of central Ethiopia. The low percentage of farmers currently growing local varieties in the three districts are likely the result of commendable expansion of well performing modern varieties.

The results found in the current survey and previous research reports were comparable to those obtained in direct farm assessment. The different approaches followed may account for the large variations observed on the extent of genetic erosion although the trends were similar between the altitudes. The findings of the study have a significant impact for in situ conservation of landraces for future use in breeding to combat the challenges of climate change. Farmers' opinions gathered in group discussions indicated that drought contributed to high loss of landraces in Ada and Lume and the result contradicts the existing theory that landraces are well adapted and coevolved in the environment they originated.

The results contribute to the setting of targeted strategies in high altitude zones for in situ conservation and exploitation of landraces in future breeding programs. Future studies should take into account direct observations as alternative approaches to assess and estimate genetic erosion of tetraploid wheat and other indigenous crop species.

\section{Acknowledgments}

The authors would like to thank the Ethiopian Institute of Agricultural Research (EIAR), Agricultural Growth Program II, (AGP II) and the International Center for Agricultural Research in the Dry Areas (ICARDA) for providing technical and financial support for the execution of the field experiments. The authors also acknowledge the support provided by WondoGenet Research Center and Debre-Zeit Research Center. Research and technical staff members of the crop research process of Debre-Zeit Research Center are highly acknowledged for assisting us in field activities.

\section{Author contributions}

A. Zemede proposed, designed, and conducted the trial, analyzed data, drafted and finalized the manuscript. F. 
Mekbib, K. Assefa and Z. Bishaw made valuable contributions to and commented on the final manuscript.

\section{Conflict of interest statement}

The authors declare that they have no competing interest.

\section{References}

Assefa, K., Cannarozzi, G., Girma, D., Kamies, R., Chanyalew, S., Plaza-Wüthrich, S., Blösch, R., Rindisbacher, A., Rafudeen, S., and Tadele, Z. (2015). Genetic diversity in tef [Eragrostis tef (Zucc.) Trotter]. Frontiers in Plant Science 6, 177. doi: https: //doi.org/10.3389/fpls.2015.00177

Bechere, E., Kebede, H., and Belay, G. (2000). Durum wheat in Ethiopia: an old crop in an ancient land (Addis Ababa: Institute of Biodiversity Conservation and Research).

Berg, T. (2009). Landraces and folk varieties: a conceptual reappraisal of terminology. Euphytica 166, 423-430. doi: https://doi.org/10.1007/s10681-0089829-8

Bishaw, Z., Struik, P. C., and Van Gastel, A. J. G. (2014). Assessment of on-farm diversity of wheat varieties and landraces: Evidence from farmer's fields in Ethiopia. African Journal of Agricultural Research 9(39), 29482963. doi: https://doi.org/10.5897/AJAR2013.7574

Brown, A. H. D. and Hodgkin, T. (2015). Indicators of Genetic Diversity, Genetic Erosion, and Genetic Vulnerability for Plant Genetic Resources. In Genetic Diversity and Erosion in Plants. Sustainable Development and Biodiversity, ed. Ahuja, M. and Jain, S., (Cham: Springer), volume 7.

Central Statistical Agency (2017). Agricultural Sample Survey 2016/17, Area and Production for Major Crops. Private Peasant Holdings. In Statistical Bulletin No 584, volume 1, Addis Ababa, Ethiopia.

Eticha, F., Belay, G., and Bekele, E. (2006). Species diversity in wheat landrace populations from two regions of Ethiopia. Genet Resour Crop Evol 53, 387393. doi: https://doi.org/10.1007/s10722-004-6095$\mathrm{z}$

FAO/IPGRI (2002). Review and development of indicators for genetic diversity, genetic erosion and genetic vulnerability (GDEV): summary report of a joint FAO/IPGRI workshop.

Gashawbeza, B., Yaekob, A., Zemede, A., Kifetew, J., Tadesse, T., and Mekuria, B. (2003). Fertilizer N Effects on Yield and Grain Quality of Durum Wheat. Tropical Agriculture 80, 146-151.

Geleta, N. and Gausgruber, H. (2013). On-Farm Diversity and Genetic Erosion of Tetraploid Wheat Landraces in Ambo and Dandi Districts, West Shewa, Ethiopia. Science, Technology and Arts Research Journal 2(1), 1-9.

Hammer, K., Knüpffer, H., Xhuveli, L., and Perrino, P. (1996). Estimating genetic erosion in landraces - two case studies. Genet Resour Crop Evol 43, 329-336. doi: https://doi.org/10.1007/BF00132952

Mengistu, D. K., Kidane, Y. G., Fadda, C., and Pè, M. E. (2016). Genetic diversity in Ethiopian Durum Wheat (Triticum turgidum var durum) inferred from phenotypic variations. Plant Genetic Resources: Characterization and Utilization 16(1), 39-49. doi: https://doi.org/10.1017/S1479262116000393

Negatu, W., Mwangi, W., and Tesema, T. (1992). Farmers' Varietal Preferences for Durum wheat in Ada, Lume and Gimbichu Woredas. Ethiopian Journal of Agricultural Science (Ethiopia) 13, 89-100.

Teklu, Y. and Hammer, K. (2006). Farmers' perception and genetic erosion of tetraploid wheat landraces in Ethiopia. Genet Resour Crop Evol 53, 1099-1113. doi: https://doi.org/10.1007/s10722-005-1145-8

Tesema, T. (1991). Research Recommendations and Future Strategies of the Ethiopian Durum Wheat Improvement Program. In Wheat Research in Ethiopia A Historical Perspective, ed. Gebre-Mariam, H., Tanner, D. G., and Hulluka, M. M., (Addis Ababa: IAR/CIMMYT), 164-170.

Tsegaye, B. and Berg, T. (2007). Genetic erosion of Ethiopian tetraploid wheat landraces in Eastern Shewa, Central Ethiopia. Genet Resour Crop Evol 54, 715-726. doi: https://doi.org/10.1007/s10722-0060016-2 